\title{
Polyaniline Deposition on the Surface of Cotton Fibers: Structural Studies, Swelling Behavior, and Water Absorption Properties
}

\author{
Tesfamariam Teklu $\mathbb{D}^{1},{ }^{1}$ Teklit Kidane Gebremedhin, ${ }^{1,2}$ Amanual Hadera Tesfay, ${ }^{1}$ \\ Asfaw Gebretsadik Gebru, ${ }^{1}$ Ykalo Hadush Desta, ${ }^{1}$ Libargachew Demlie Mihretu, ${ }^{1}$ \\ Hayal Lemma, ${ }^{3}$ Hiluf Hindeya Gebreyesus, ${ }^{4}$ and Tadele Alemayo ${ }^{5}$ \\ ${ }^{1}$ Department of Chemistry, Mekelle University, Mekelle, P.O. Box: 231, Ethiopia \\ ${ }^{2}$ Abbiyi Addi College of Teachers Education, Abbiyi Addi, P.O. Box: 11, Ethiopia \\ ${ }^{3}$ Department of Biology, Mekelle University, Mekelle, P.O. Box: 231, Ethiopia \\ ${ }^{4}$ School of Medical Sciences, Mekelle University, Mekelle, P.O. Box: 231, Ethiopia \\ ${ }^{5}$ Department of Animal Rangeland and Wildlife Science, Mekelle University, Mekelle, P.O. Box: 231, Ethiopia
}

Correspondence should be addressed to Tesfamariam Teklu; betynatan@gmail.com

Received 23 August 2019; Revised 4 December 2019; Accepted 7 January 2020; Published 7 March 2020

Academic Editor: Veronica Calado

Copyright (c) 2020 Tesfamariam Teklu et al. This is an open access article distributed under the Creative Commons Attribution License, which permits unrestricted use, distribution, and reproduction in any medium, provided the original work is properly cited.

\begin{abstract}
Polyaniline-modified natural fibers have been recognized as promising candidates for conductive clothes, UV protection, and electromagnetic interference shielding. Hence, the purpose of this study was to investigate the effect of surface deposition of cotton fibers using polyaniline via in situ polymerization, and preceding structural changes were further screened by FT-IR, UV-Vis, TGA, SEM/EDX, and conductivity in comparison with bare cotton fibers used as the control sample. Polyaniline was introduced on the surface of cotton fibers as a conductive form, which was confirmed by electrical conductivity $\left(1.54 \times 10^{-4} \mathrm{Scm}^{-1}\right) \mathrm{equivalent}$ to semiconductor materials. Detection of particular peaks at $\mathrm{NK} \alpha 0.379 \mathrm{keV}$ and $\mathrm{ClK} \alpha 2.621 \mathrm{keV}$ from EDX analysis revealed the introduction of nitrogen and chlorine, respectively. Polyaniline deposition on the cotton surface was successful to introduce hydrophobic environment to the system to enhance resistance to water absorption meaningfully.
\end{abstract}

\section{Introduction}

The inherent features of conducting polymers have attracted considerable attention of scientists and researchers. Polyaniline (PAni) is one among such polymers, which uses the least expensive monomer with the advantage of the ease of polymerization $[1,2]$. Electronic structure of polyaniline can be altered by varying the ratio of oxidation-reduction states of amino functionalities, which includes fully reduced leucoemeraldine, completely oxidized pernigraniline, and partially oxidized emeraldine forms (Figure 1) [3]. This can be achieved by adding oxidizing or reducing agents under varied reaction media.

Polyaniline backbone is wealthy in amine and imine multifunctionalities comprised of benzoid (-B-NH-B-NH-) and quinoid (-B-N=Q-N=) ${ }_{n}$ repeating structures [4], which are responsible for the fascinating features of surface chemistry. Sole polyaniline exists in the form of aggregated [5] powder which has limited surface area [6], poor processability, and weak mechanical strength [7]. These drawbacks hindered the scope, versatility, and multidisciplinary applications of polyaniline. Hence, different substrates and modifiers are required to obtain functionally active materials that display enhanced properties and performances. Natural fibers such as kenaf, cotton, jute, kapok, and banana [8-11] are suitable candidates used as a substrate phase to carry polyaniline.

Polyaniline salt has played a key role as a conductive filler in the production of electrically conductive fabrics such as cotton, coconut, nylon, and polyester $[12,13]$, which are used as antistatic coatings, pressure-sensing, electromagnetic interference shielding, and UV protection [14]. Elecroconductive fabrics, particularly polyaniline-based cotton textiles, show considerable applications in wearable electronics, 
<smiles>CNC1=CC=C(Nc2ccc(Nc3ccc(Nc4ccc(C)cc4)cc3)cc2)CC1</smiles>

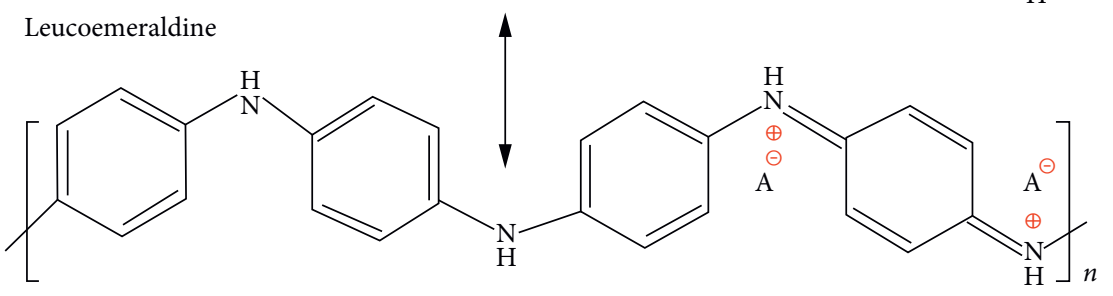

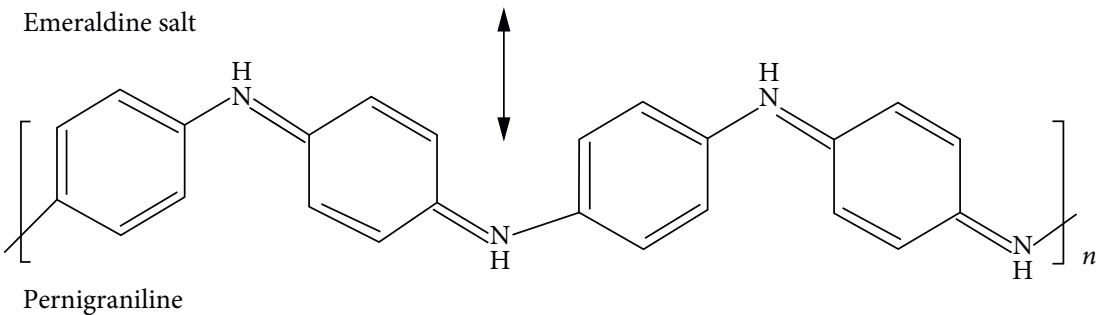

FIgURE 1: Molecular design of oxidation states of polyaniline, where $\mathrm{A}^{-}$denotes anionic species.

sensory devices, heating utensils, recovery of precious metals, and environmental remediations [7, 15]. Among many substrates, cotton (Gossypium hirsutum) fiber belongs to the Gossypieae tribe, which grows comfortably in the USA, South America, India, Egypt, Sudan, South Africa, and Ethiopia [16]. It has a soft and crystalline fibrous structure, which possesses a fairly strong mechanical property and low density [17].

Polyaniline deposition can be done by in situ oxidative polymerization [18-20]. It is termed as nondestructive technique which does not require removal of template materials. Moreover, in situ oxidative polymerization is a proven method to avoid aggregate formation in order to maximize the surface area, which is known to be a suitable technique for mass production at reasonable costs [21]. However, application of natural fibers as a substrate phase has certain shortcomings such as high moisture regain when exposed to water results swelling [22]. Consequently, in situ deposition of polyaniline on the surface of natural fibers is supposed to introduce hydrophobic polymer matrix by reducing water absorption features of the fibers [23].

Therefore, the present study is primarily targeted to investigate the influence of polyaniline deposition on the surface of cotton fibers by in situ oxidative polymerization. Besides, the effect of surface modification using polyaniline on structural features of cotton fibers was investigated by Fourier transform-infrared (FT-IR) spectroscopy, UV-Visible (UVVis) spectroscopy, thermogravimetric analysis (TGA), scanning electron microscope (SEM) coupled with energy dispersive X-ray (EDX) spectroscopy, and electrical conductivity.

\section{Materials and Methods}

2.1. Chemicals and Materials. The following reagents were of analytical grade and used without further purification: aniline $\left(\mathrm{C}_{6} \mathrm{H}_{7} \mathrm{~N}\right)$, ferric chloride hexahydrate $\left(\mathrm{FeCl}_{3} \cdot 6 \mathrm{H}_{2} \mathrm{O}\right)$, hydrochloric acid $(\mathrm{HCl})$, chloroform $\left(\mathrm{CHCl}_{3}\right)$, acetone $\left(\mathrm{C}_{3} \mathrm{H}_{6} \mathrm{O}\right)$, and ethanol $\left(\mathrm{C}_{2} \mathrm{H}_{5} \mathrm{OH}\right)$ purchased from Merck Chemical Co. (Germany), through a local agency. Cotton (Gossypium hirsutum) fiber was obtained from the local market of Mekelle, Northern Ethiopia. It was washed with double distilled water, followed by acetone and ethanol, and finally dried in air at room temperature.

2.2. Chemical Deposition of Polyaniline on the Surface of Cotton Fibers. Chemical deposition of polyaniline on the surface of cotton fibers was carried out using the following procedure. $10 \mathrm{gm}$ of cotton fiber was soaked in $0.2 \mathrm{M} \mathrm{HCl}$ solution on stirring. $150 \mathrm{~mL}$ of $0.5 \mathrm{M}$ aniline was added into the flask containing acidified fiber on subsequent stirring. Equimolar of ferric chloride hexahydrate solution was added into the mixture dropwise while stirring [8, 24], and the polymerization process was allowed for 12 hours at room temperature. Polyaniline-deposited cotton fiber was filtered and washed with dilute $\mathrm{HCl}$ solution followed by doubledistilled water repeatedly until the filtrate became colorless. It was oven-dried at $50^{\circ} \mathrm{C}$.

2.3. Character Studies. Bare cotton fibers and polyanilinedeposited cotton fibers were characterized using Fourier transform-infrared (FT-IR) spectrometer (IRAffinity-1S, Shimadzu) via $\mathrm{KBr}$ disk technique in a spectral range of $4000-400 \mathrm{~cm}^{-1}$. Both samples were subjected to thermal analysis on the simultaneous thermal analyzer (DSC-TGA SDT-Q600) with the following parameters: a continuous nitrogen flow $(20 \mathrm{ml} / \mathrm{min})$ and a heating rate of $40^{\circ} \mathrm{C} / \mathrm{min}$ from $25^{\circ} \mathrm{C}$ to $600^{\circ} \mathrm{C}$. The surface morphology of bare and polyaniline-deposited cotton fibers was observed using a highly customizable scanning electron microscope (SEM) (JSM-IT300LV, JEOL, USA) coupled with a port for 


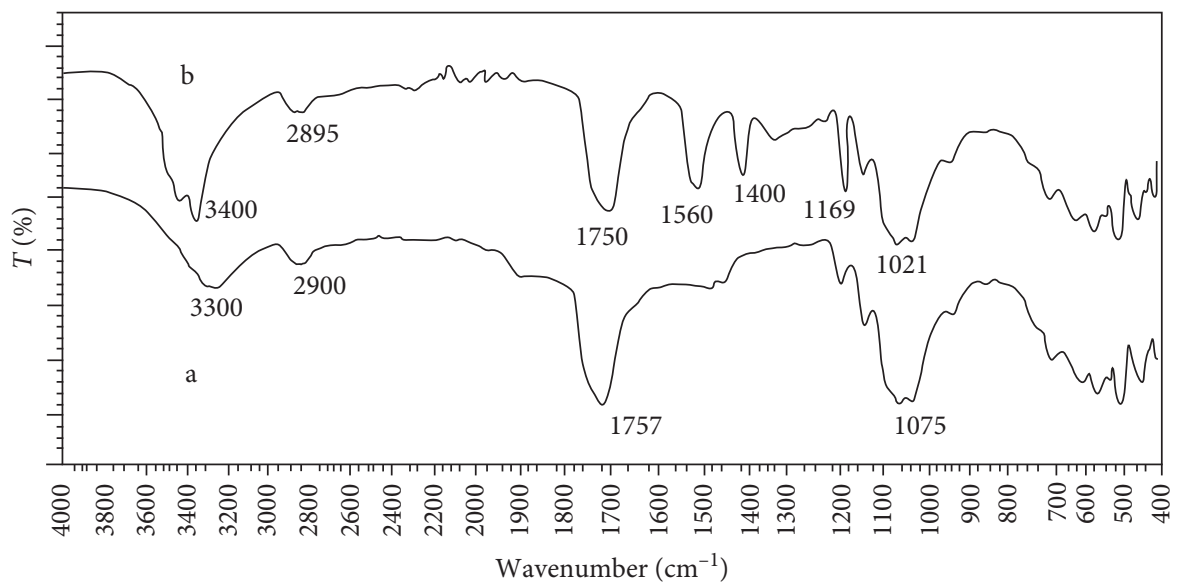

FIGURE 2: FT-IR spectra of (a) bare cotton fibers and (b) polyaniline-deposited cotton fibers.

analytical attachment of energy dispersive X-ray (EDX) spectrometry. The samples were gold-coated by the sputtering technique to avoid charging and observed under different magnifications.

2.4. Washability Test for Polyaniline. Polyaniline-deposited cotton fiber immersed in chloroform and deionized water (as control) is exposed to Mesdan Autowash with a speed of $40 \mathrm{rpm}$ at $60^{\circ} \mathrm{C}$ for 90 minutes wash time. The concentration of extracted polyaniline was then analyzed using PerkinElmer Lambda 9 UV-Visible spectrophotometer in the wavelength region of $200-800 \mathrm{~nm}$ [25].

2.5. Water Absorption. Water absorption studies were performed according to ASTM D 570-99 method [26] with minor modifications. $1 \mathrm{~g}$ of bare and polyaniline-deposited cotton fiber specimens were prepared for water absorption experiment. Each specimen was fully immersed and soaked in double-distilled water for 12 hours at room temperature. At the end of the immersion, the samples were taken out from the water, the surface water was taken off using tissue, and wet weight values were measured and reported in weight percent.

2.6. Swelling Behavior. Swelling behavior of cotton and polyaniline-deposited cotton fiber was measured using an optical microscope which is well fitted with a high-resolution Leica camera. It also had image analysis software (Mesdan video analyzer) which allowed the measurement of fiber diameter at various points [25]. The presented diameter was an average of measurements taken at ten different locations along the fiber length.

2.7. Electrical Conductivity Tests. Electrical conductivity of polyaniline-deposited cotton fibers was measured using a portable conductometer device (Hanna Instruments HI 8033) by dissolving in chloroform.

\section{Results and Discussion}

3.1. Fourier Transform-Infrared (FT-IR) Spectroscopy. Weak bands at 2900 and $2895 \mathrm{~cm}^{-1}$ (Figure 2) correspond to $\mathrm{CH}$ symmetric stretching vibration of hydrocarbons derived from cellulose of cotton fibers. The intense peak at 1757 and $1750 \mathrm{~cm}^{-1}$ is recognized as $\mathrm{C}=\mathrm{O}$ stretching vibration of carbonyl groups of cellulose [27] derived from cotton fibers. It is noticeable that there is a slight shift toward lower wavelength and diminished peak intensity as a result of polyaniline deposition, which might be attributed to weaker penetration capacity of infrared energy [28]. Appearance of new bands at 1400 and $1560 \mathrm{~cm}^{-1}$ represents C-N stretching vibration of benzoid $(\mathrm{N}-\mathrm{B}-\mathrm{N})$ and $\mathrm{C}=\mathrm{N}$ stretching mode of quinoid $(\mathrm{N}=\mathrm{Q}=\mathrm{N})$ ring, respectively, which confirmed the deposition of polyaniline in the partially oxidized form, emeraldine salt. The peak at $1169 \mathrm{~cm}^{-1}$ is characteristic of polyaniline conductivity, which is a measure of electron delocalization [7]. The common band around 1021 and $1075 \mathrm{~cm}^{-1}$ belongs to $\mathrm{C}-\mathrm{O} \beta$-glycosidic linkage of glucose [29] in cellulose.

Furthermore, the peak at approximately $3400 \mathrm{~cm}^{-1}$ belongs to $\mathrm{N}-\mathrm{H}$ stretching vibration of the amino group. This shows the existence of polyaniline [30] within the fiber structures, which proved inclusion of polyaniline as a result of in situ chemical polymerization. The other band at $3300 \mathrm{~cm}^{-1}$ in the bare cotton fibers (Figure 2(a)) represents $\mathrm{O}-\mathrm{H}$ stretching vibrations which confirmed the presence of hydrogen bonding within the cellulose of cotton fibers [31].

3.2. Washability Tests via UV-Visible Spectroscopy. The filtrate after washing in chloroform was visually identified, and a greenish solution alongside faded cotton fibers was observed. From UV-Vis absorption spectra of chloroform filtrate solution, three distinct bands are visualized. The strong absorption peak at the maximum wavelength $\left(\lambda_{\max }\right)$ of $300 \mathrm{~nm}$ (Figure $3(\mathrm{~b})$ ) represents $\pi-\pi^{*}$ transition from benzoid (N-B-N) ring of the polyaniline backbone. The other peak which appears at $425 \mathrm{~nm}$ is the feature of polaron- $\pi^{*}$ transitions. One final band at $610 \mathrm{~nm}$ is assigned to $\pi$-polaronic transitions $[32,33]$. These evidences proved that 


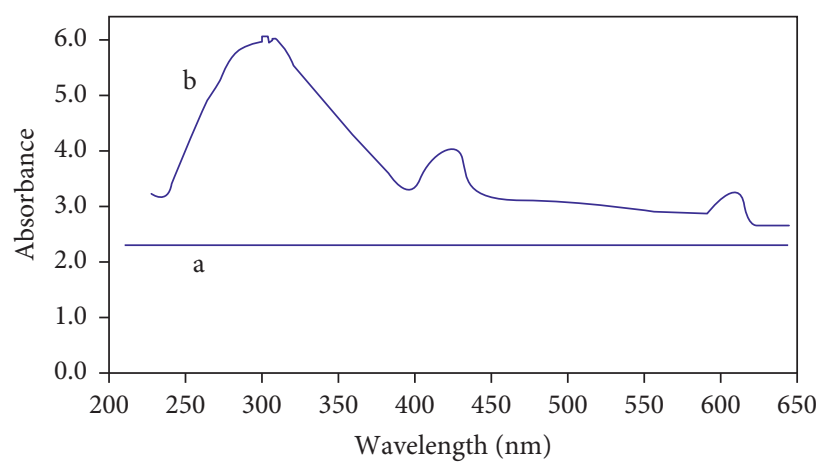

Figure 3: UV-Vis spectra of polyaniline-deposited cotton fibers in [(a) deionized water and (b) chloroform], respectively.

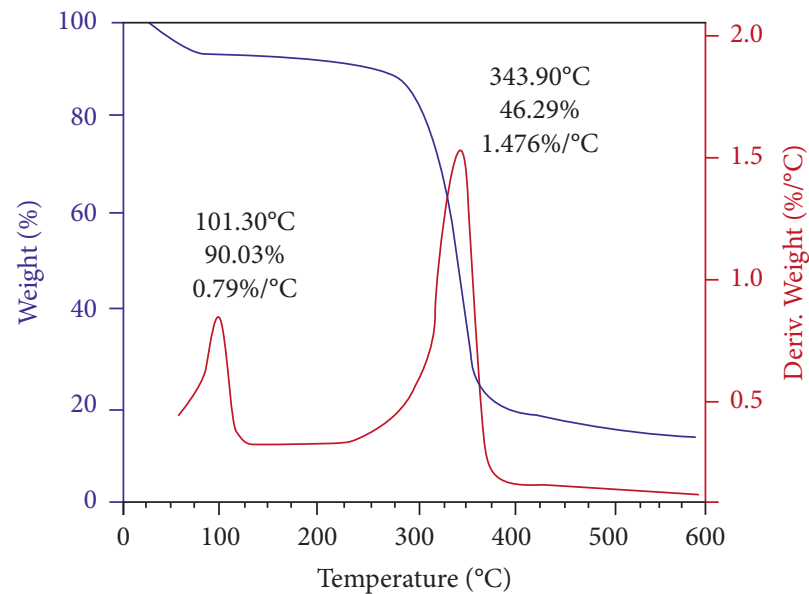

(a)

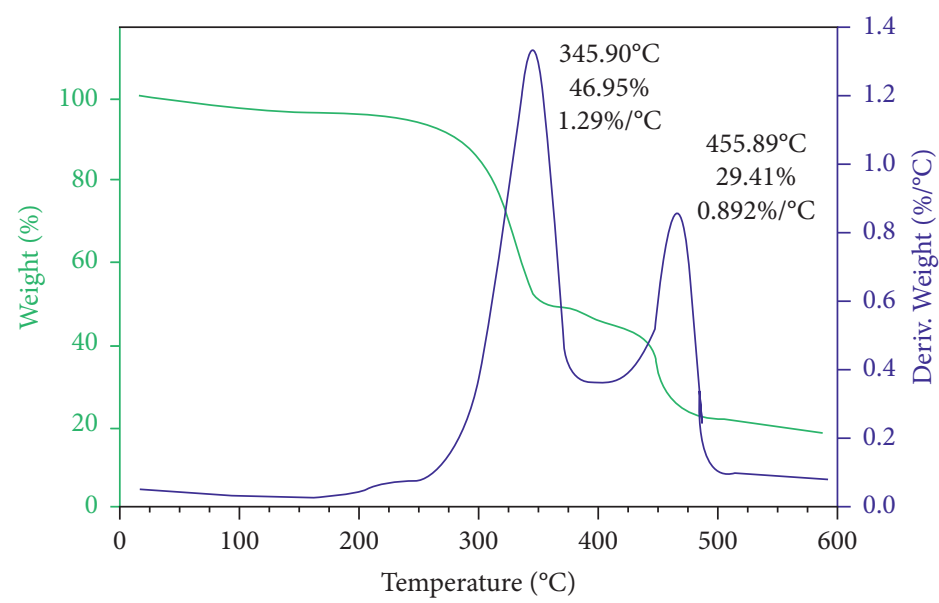

(b)

FIGURE 4: TGA thermogram of (a) bare cotton fibers and (b) polyaniline-deposited cotton fibers.

polyaniline was deposited either by weak chemical intact or via simple physical means. No absorption peak was observed in the deionized water filtrate solution (Figure 3(a)). This is an evidence that polyaniline is insoluble in water and in other polar media. Results of this study are in good agreement with prior works by the authors on sisal fibers [25].
3.3. Thermogravimetry Analysis (TGA). The upper stage of the thermogram of bare cotton fibers (Figure 4(a)) which extends up to $101^{\circ} \mathrm{C}$ is due to the evolution of moisture content within the fiber structure. The second step at approximately $344^{\circ} \mathrm{C}$ shows the breakage of the glycosidic link and bond cleavage of $\mathrm{C}-\mathrm{H}, \mathrm{C}-\mathrm{C}$, and $\mathrm{C}-\mathrm{O}$ from the cellulose of cotton fibers [34]. 
TABLE 1: Weight loss of bare cotton fibers and polyaniline-deposited cotton fibers as a function of temperature.

\begin{tabular}{lccc}
\hline Sample & Temperature $\left({ }^{\circ} \mathrm{C}\right)$ & Weight loss $(\%)$ & Process \\
\hline \multirow{3}{*}{$20 \mathrm{mg}$ of bare cotton fiber } & $60-120$ & 9.42 & Dehydration of water/moisture \\
& $275-400$ & 53.71 & Decomposition of organic matter \\
& $400-600$ & - & - \\
$20 \mathrm{mg}$ of polyaniline-deposited cotton fiber & $60-130$ & - & - \\
& $385-375$ & 53.05 & Decomposition of organic matter \\
\end{tabular}
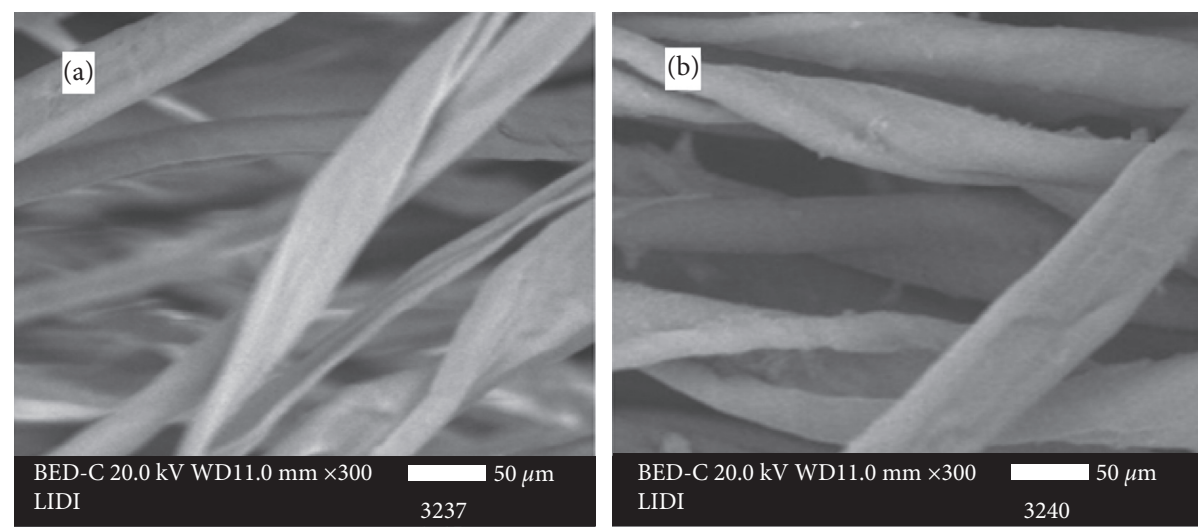

FIGURE 5: SEM micrographs of (a) bare cotton fibers and (b) polyaniline-deposited cotton fibers.

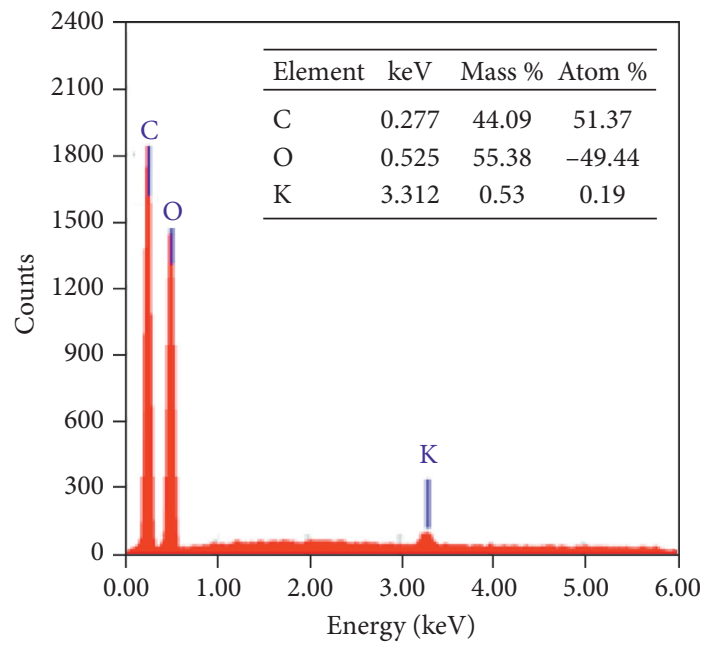

(a)

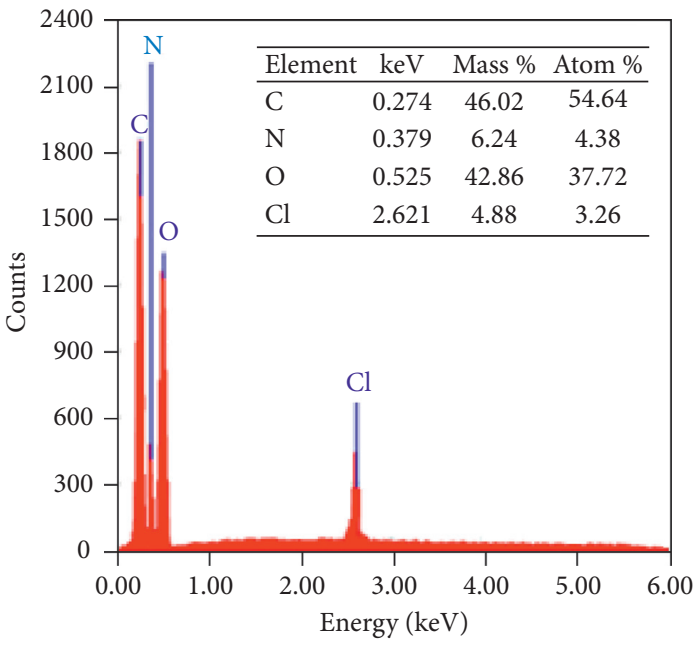

(b)

Figure 6: EDX spectra of (a) bare cotton fibers and (b) polyaniline-deposited cotton fibers.

In the case of polyaniline-deposited cotton fibers (Figure 4(b)), the first stage at $346^{\circ} \mathrm{C}$ represents the bond cleavage of $\mathrm{C}-\mathrm{H}, \mathrm{C}-\mathrm{C}$, and $\mathrm{C}-\mathrm{O}$ from the cellulose of cotton fibers. The last stage beyond $456^{\circ} \mathrm{C}$, which is thermally stable compared to the bare cotton fibers, represents a degradation of the polyaniline backbone (Table 1) [35].

3.4. Surface Morphology (SEM/EDX). Polyaniline deposition has shown considerable variations on the surface morphology of cotton fibers. At a glance of naked eye, in situ polymerization has completely changed white cotton fibers to dark green suggesting that a conductive form of polyaniline was introduced [3]. The surface morphology of polyaniline-coated cotton fibers (Figure 5(b)) revealed that major section of the surface is full of roughness and fluffy fur or needle-like structures, while SEM micrograph of bare cotton fibers (Figure 5(a)) is smooth and clean. These morphological variations might be a result of polyaniline deposition on the surface of cotton fibers.

EDX spectrum (Figure 6(b)) showed the appearance of new peaks in $\mathrm{NK} \alpha 0.379 \mathrm{keV}$ and $\mathrm{ClK} \alpha 2.621 \mathrm{keV}$ [23], which proved that polyaniline was successfully deposited on the surface of cotton fibers. Detection of such peaks 
TABLE 2: Water absorption, swelling behavior (in terms of diameter), and electrical properties of bare cotton fibers and polyanilinedeposited cotton fibers.

\begin{tabular}{|c|c|c|c|c|c|c|c|}
\hline \multirow{2}{*}{ Sample } & \multirow{2}{*}{ Fiber diameter $(\mu \mathrm{m})$} & \multicolumn{3}{|c|}{ Electrical conductivity $\left(\mathrm{Scm}^{-1}\right)$} & \multicolumn{3}{|c|}{ Water absorption (12 h) (\%) } \\
\hline & & Cycle I & Cycle II & Cycle III & Cycle I & Cycle II & Cycle III \\
\hline Bare cotton fibers & 26.12 & $3.42 \times 10^{-10}$ & $3.25 \times 10^{-10}$ & $3.39 \times 10^{-10}$ & 26.3 & 25.9 & 25.82 \\
\hline Polyaniline-deposited cotton fibers & 46.93 & $1.54 \times 10^{-4}$ & $7.01 \times 10^{-7}$ & $4.2 \times 10^{-8}$ & 3.4 & 14.6 & 16.5 \\
\hline
\end{tabular}

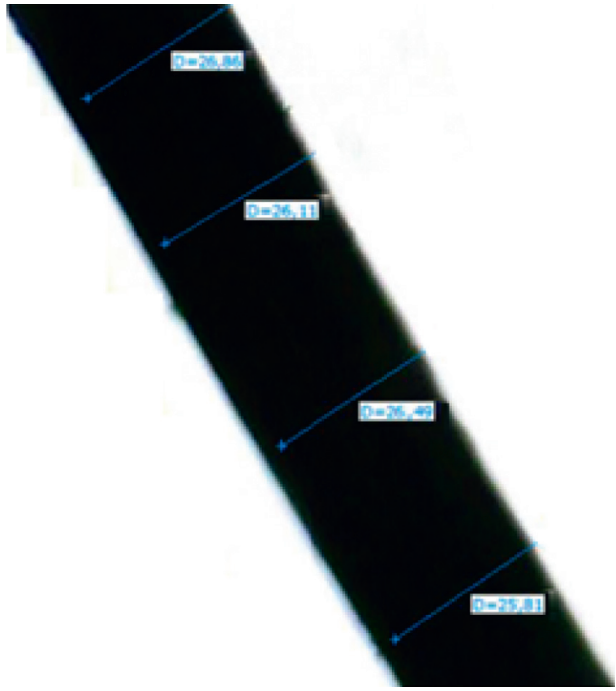

(a)

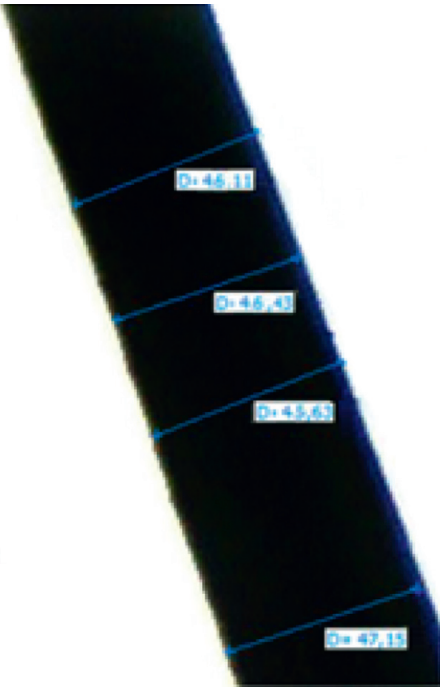

(b)

FIGURE 7: Image of optical microscope of (a) bare cotton fibers and (b) polyaniline-deposited cotton fibers.

confirmed the inclusion of chlorine (counter anion) as dopant and nitrogen from the polyaniline backbone, respectively [8, 37]. Existence of trace impurities such as potassium (Figure 6(a)) might be introduced from the reactants, solvents, and the fiber itself and was removed during in situ oxidative polymerization.

3.5. Water Absorption. Water absorption (equation (1)) data of bare and polyaniline-deposited cotton fibers calculated by weight difference are shown in Table 2. The experimental water absorption data of cotton fibers were $26.3 \%$ which abruptly dropped to $3.4 \%$ up on the subsequent polyaniline deposition $[25,38]$. This incidence proved that the surface chemistry of cotton fibers is notably hydrophilic $[17,39]$, which is diminished up on in situ deposition of polyaniline thereby introducing hydrophobicity to the system [25,39]. Water absorption features of polyaniline-deposited cotton fibers are increased on further washing by chloroform (compare values of cycle II and III).

$$
\text { Water absorption }(\%)=\left(\frac{W_{\mathrm{w}}-W_{\mathrm{d}}}{W_{\mathrm{d}}}\right) \times 100 \text {, }
$$

where $W_{\mathrm{d}}$ and $W_{\mathrm{w}}$ are the dry and wet weights of cotton fibers before and after soaking in the water system, respectively.
3.6. Swelling Behavior. In situ deposition of polyaniline on the surface of cotton fibers as a function of swelling (fiber diameter) recorded from optical microscope is summarized in Table 2. Thickness of cotton fibers (expressed in terms of fiber diameter) was increased by about 20 microns as a result of in situ deposition of polyaniline. The enhancement of fiber thickness is clearly visualized using markings from optical microscope (Figure 7). Even though the researchers are unable to fully support using other experimental evidences, data of swelling behavior show impregnation of polyaniline to the inner structures of cotton fibers [40].

3.7. Electrical Conductivity Studies. The electrical conductivity of bare cotton fibers is $3.42 \times 10^{-10} \mathrm{Scm}^{-1}$ while that of polyaniline-deposited cotton fibers was $1.54 \times 10^{-4} \mathrm{Scm}^{-1}$. Based on the level of conductivity, polyaniline-deposited cotton fibers lie in the semiconducting level, which is a clear evidence that polyaniline is deposited in its partially oxidized salt form $[8,41]$. The level of electrical conductivity decreased significantly on further washing by chloroform (Table 2), which confirmed fade out of chemically deposited polyaniline via physical process. However, repeated washing could not nullify electrical conductivity which might be due to the existence of impregnated polyaniline within the fiber interstructures. This incidence is further supported by water absorption data (Table 2). 


\section{Conclusion}

The main findings are summarized in the following manner:

(i) Peaks from EDX spectra at $\mathrm{NK} \alpha 0.379 \mathrm{keV}$ and $\mathrm{ClK} \alpha 2.621 \mathrm{keV}$ proved inclusion of polyaniline in the salt form, emeraldine salt

(ii) Introduction of polyaniline changed nonconducting cotton fibers $\left(3.42 \times 10^{-10} \mathrm{Scm}^{-1}\right)$ to semiconductor materials $\left(1.54 \times 10^{-4} \mathrm{Scm}^{-1}\right)$

(iii) Polyaniline deposition on cotton fibers reduced water absorption features by about $20 \%$ relative to the bare cotton fibers

(iv) SEM microstructures confirmed formation of fluffy fur or needle like structures up on polyaniline deposition compared to smoother cotton fibers

Hence, polyaniline was successfully deposited on the surface of cotton fibers using iron (III) chloride as oxidant and dopant via in situ oxidative polymerization route which was verified via spectroscopic and microscopic instruments.

\section{Data Availability}

The data used to support the findings of this study are available from the corresponding author upon request.

\section{Conflicts of Interest}

The authors declare that there are no conflicts of interest.

\section{Acknowledgments}

The corresponding author gratefully acknowledges the financial support from Mekelle University (scheme number: MU/CNCS/001/2011) and International Foundation of Science (IFS) (scheme number: I-2-W-6248-1).

\section{References}

[1] Y. S. Negi and P. V. Adhyapak, "Development in polyaniline conducting polymers," Journal of Macromolecular Science, Part C: Polymer Reviews, vol. 42, no. 1, pp. 35-53, 2002.

[2] S.-B. Yoon, E.-H. Yoon, and K.-B. Kim, "Electrochemical properties of leucoemeraldine, emeraldine, and pernigraniline forms of polyaniline/multi-wall carbon nanotube nanocomposites for supercapacitor applications," Journal of Power Sources, vol. 196, no. 24, pp. 10791-10797, 2011.

[3] V. S. Jamadade, D. S. Dhawale, and C. D. Lokhande, "Studies on electrosynthesized leucoemeraldine, emeraldine and pernigraniline forms of polyaniline films and their supercapacitive behavior," Synthetic Metals, vol. 160, no. 9-10, pp. 955-960, 2010.

[4] D. C. Trivedi, "Dopant induced solubilization of conducting polyaniline," Indian Journal of Chemistry, vol. 33A, pp. 552-557, 1994.

[5] S. Piri, Z. A. Zanjani, F. Piri, A. Zamani, M. Yaftian, and M. Davari, "Potential of polyaniline modified clay nanocomposite as a selective decontamination adsorbent for $\mathrm{Pb}(\mathrm{II})$ ions from contaminated waters; kinetics and thermodynamic study," Journal of Environmental Health Science and Engineering, vol. 14, no. 20, pp. 1-10, 2016.
[6] F. Kanwal, R. Rehman, T. Mahmud, J. Anwar, and R. Ilyas, "Isothermal and thermodynamical modeling of chromium (iii) adsorption by composites of polyaniline with rice husk and saw dust," Journal of the Chilean Chemical Society, vol. 57, no. 1, pp. 1058-1063, 2012.

[7] N. Onar, A. C. Akşit, M. F. Ebeoglugil, I. Birlik, E. Celik, and I. Ozdemir, "Structural, electrical, and electromagnetic properties of cotton fabrics coated with polyaniline and polypyrrole," Journal of Applied Polymer Science, vol. 114, no. 4, pp. 2003-2010, 2009.

[8] S. I. A. Razak, W. A. W. A. Rahman, S. Hashim, and M. Y. Yahya, "In situ surface modification of natural fiber by conducting polyaniline," Composite Interfaces, vol. 19, no. 6, pp. 365-376, 2012.

[9] T. Q. Hao, Y. Z. Zhan, B. J. Liu, W. Wang, and D. Yu, "Preparation of polyaniline/cotton composite for Cr (VI) removal in solution," Advanced Materials Research, vol. 1142, pp. 285-290, 2017.

[10] P. A. Kumar, S. Chakraborty, and M. Ray, "Removal and recovery of chromium from wastewater using short chain polyaniline synthesized on jute fiber," Chemical Engineering Journal, vol. 141, no. 1-3, pp. 130-140, 2008.

[11] Y. Zheng, W. Wang, D. Huang, and A. Wang, "Kapok fiber oriented-polyaniline nanofibers for efficient $\mathrm{Cr}(\mathrm{VI})$ removal," Chemical Engineering Journal, vol. 191, pp. 154-161, 2012.

[12] C. Merlini, G. M. O. Barra, D. P. Schmitz et al., "Polyanilinecoated coconut fibers: structure, properties and their use as conductive additives in matrix of polyurethane derived from castor oil," Polymer Testing, vol. 38, pp. 18-25, 2014.

[13] N. Muthukumar and G. Thilagavathi, "Development and characterization of electrically conductive polyaniline coated fabrics," Indian Journal of Chemical Technology, vol. 19, pp. 434-441, 2012.

[14] A. S. Altinok, I. Ucgul, and A. U. Oksuz, "Production of polyester/polyaniline, cotton/polyaniline composite fabrics and examining electrical characteristics," Tekstil Ve Konfeksiyon, vol. 24, no. 1, pp. 21-25, 2014.

[15] R. Perumalraj, "Electrical surface resistivity of polyaniline coated woven fabrics," Journal of TextileScience and Engineering, vol. 5, no. 3, pp. 1-5, 2015.

[16] G. E. Nicholson, "The production, history, uses and relationships of cotton (gossypium spp.) in Ethiopia (gossypium spp.) in Ethiopia," Economic Botany, vol. 14, no. 1, pp. 3-36, 1960.

[17] S. Maity and A. Chatterjee, "Textile/polypyrrole composites for sensory applications," Journal of Composites, vol. 2015, Article ID 120516, 6 pages, 2015.

[18] X. Jiang, T. Dai, and Y. Lu, "Fabrication of polypyrrole hollow Y-junction and capsule using azo-dye templates," Iranian Polymer Journal, vol. 17, no. 8, pp. 645-651, 2008.

[19] A. Kaynak, S. S. Najar, and R. C. Foitzik, "Conducting nylon, cotton and wool yarns by continuous vapor polymerization of pyrrole," Synthetic Metals, vol. 158, no. 1-2, pp. 1-5, 2008.

[20] A. Reung-U-Rai, A. Prom-Jun, W. Prissanaroon-Ouajai, and S. Ouajai, "Synthesis of highly conductive polypyrrole nanoparticles via microemulsion polymerization," Journal of Metals, Materials and Minerals, vol. 18, no. 2, pp. 27-31, 2008.

[21] P. Lekpittaya, N. Yanumet, B. P. Grady, and E. A. O’Rear, "Resistivity of conductive polymer-coated fabric," Journal of Applied Polymer Science, vol. 92, no. 4, pp. 2629-2636, 2004.

[22] J. Cruz, A. Leitão, D. Silveira, S. Pichandi, M. Pinto, and R. Fangueiro, "Study of moisture absorption characteristics of cotton terry towel fabrics," Procedia Engineering, vol. 200, pp. 389-398, 2017.

[23] J. Molina, M. F. Esteves, J. Fernández, J. Bonastre, and F. Cases, "Polyaniline coated conducting fabrics. Chemical 
and electrochemical characterization," European Polymer Journal, vol. 47, pp. 2003-2015, 2011.

[24] F. Z. Engin and I. Usta, "Electromagnetic shielding effectiveness of polyester fabrics with polyaniline deposition," Textile Research Journal, vol. 84, no. 9, pp. 903-912, 2014.

[25] T. Teklu, L. M. Wangatia, and E. Alemayehu, "Effect of surface modification of sisal fibers on water absorption and mechanical properties of polyaniline composite," Polymer Composites, vol. 40, no. S1, pp. E46-E52, 2019.

[26] ASTM Standard D 570-99, "Standard test methods for water absorption of plastics," Annual Book of ASTM Standard, vol. 2002, 2002.

[27] S. Sakthivel and A. Boopathi, "Characterisation study of conjugated polymer polypyrrole coated cotton fabric," Journal of Pure Applied and Industrial Physics, vol. 5, no. 4, pp. 111-116, 2015.

[28] A. J. Patil and S. C. Deogaonkar, "A novel method of in situ chemical polymerization of polyaniline for synthesis of electrically conductive cotton fabrics," Textile Research Journal, vol. 82, no. 15, pp. 1517-1530, 2012.

[29] H. Zhang, L. Zhu, and R. Sun, "Structure and properties of cotton fibers modified with titanium sulfate and urea under hydrothermal conditions," Journal of Engineered Fibers and Fabrics, vol. 9, no. 1, pp. 67-75, 2014.

[30] J. Vivekanandan, V. Ponnusamy, and A. Mahudeswaran, "Synthesis, characterization and conductivity study of polyaniline prepared by chemical oxidative and electrochemical methods," Archives of Applied Science Research, vol. 3, no. 6, pp. 147-153, 2011.

[31] W. Xu, B. Mu, W. Zhang, and A. Wang, "Facile fabrication of well-defined polyaniline microtubes derived from natural kapok fibers for supercapacitors with long-term cycling stability," RSC Advances, vol. 6, pp. 68304-68311, 2016.

[32] S. Ito, K. Murata, S. Teshima et al., "Simple synthesis of watersoluble conducting polyaniline," Synthetic Metals, vol. 96, no. 2, pp. 161-163, 1998.

[33] J. Fernando and C. Vedhi, "Synthesis, spectral and electrochemical characterization of adipic acid doped polyaniline," The Interanational Journal of Science and Technology, vol. 3, no. 4, pp. 166-173, 2015.

[34] H. Yang, R. Yan, H. Chen, D. H. Lee, and C. Zheng, "Characteristics of hemicellulose, cellulose and lignin pyrolysis," Fuel, vol. 86, no. 12-13, pp. 1781-1788, 2007.

[35] A. Esfandiari, "PPy covered cellulosic and protein fibres using novel covering methods to improve the electrical property," World Applied Sciences Journal, vol. 3, no. 3, pp. 470-475, 2008.

[36] A. Kumar, A. Mishra, K. Awasthi, and V. Kumar, "Thermal stability and electrical properties of polyaniline synthesized by oxidative polymerization method," Macromolecular Symposia, vol. 357, no. 1, pp. 168-172, 2015.

[37] B. I. Hassel, S. Trey, S. Leijonmarck, and M. Johansson, “A study on the morphology, mechanical and electrical performance of polyaniline-modified wood-a semiconducting composite material," BioResources, vol. 9, no. 3, pp. 5007-5023, 2014.

[38] W. He, J. Li, J. Tian, H. Jing, and Y. Li, "Characteristics and properties of wood/polyaniline electromagnetic shielding composites synthesized via in situ polymerization," Polymer Composites, vol. 39, no. 2, pp. 537-543, 2016.

[39] T. Fakhrul and M. A. Islam, "Degradation behavior of natural fiber reinforced polymer matrix composites," Procedia Engineering, vol. 56, pp. 795-800, 2013.

[40] W. He, X. Zhang, C. Yu, D. Huang, and Y. Li, "Synthesis of bamboo/polyaniline composites by in situ polymerization and their characteristics," BioResources, vol. 10, no. 2, pp. 2969-2981, 2015.

[41] T. Teklu, L. M. Wangatia, and E. Alemayehu, "Sisal fibers coated with conducting polyaniline: property and structural studies," Polymer Science, Series B, vol. 59, no. 5, pp. 624-629, 2017. 